\title{
Bridging Bench and Practice: Translational Research for Schizophrenia and Other Psychotic Disorders
}

\author{
Philip S Wang ${ }^{\star, 1}$, Robert Heinssen ${ }^{1}$, Molly Oliveri ${ }^{2}$, Ann Wagner ${ }^{2}$ and Wayne Goodman ${ }^{3}$ \\ ${ }^{1}$ Division of Services and Intervention Research, National Institute of Mental Health, Rockville, MD, USA; ${ }^{2}$ Division of \\ Developmental Translational Research, National Institute of Mental Health, Rockville, MD, USA; ${ }^{3}$ Division of Adult Translational \\ Research, National Institute of Mental Health, Rockville, MD, USA
}

\begin{abstract}
Translational research is urgently needed to turn basic scientific discoveries into widespread health gains and nowhere are these needs greater than in conditions such as schizophrenia and other psychotic disorders. In this article, we discuss one type of translational research — called T1 — which is needed to take advantage of developments in the basic neurosciences and translate them into more efficacious diagnostic, preventive, and therapeutic interventions. However, ensuring that interventions from $\mathrm{T} 1$ research actually benefit patients will require a second form of translational research — called T2 - to turn innovations into everyday clinical practice and health decision-making. Recent examples of T1 and T2 research in schizophrenia and other psychotic disorders as well as strategies for better linking T1 and T2 research agendas are covered. Neuropsychopharmacology Reviews (2009) 34, 204-212; doi: I0.1038/npp.2008. 170; published online I October 2008
\end{abstract}

Keywords: translational research; schizophrenia; psychotic disorders

\section{INTRODUCTION}

"It is the responsibility of those of us involved in today's biomedical research enterprise to translate the remarkable scientific innovations we are witnessing into health gains for the nation. In order to address this imperative, we at the National Institutes of Health (NIH) asked ourselves: What novel approaches can be developed that have the potential to be truly transforming for human health?"

Elias A Zerhouni, M.D., Translational and clinical science-time for a new vision. NEJM 2005; 353:1621-1623.

Other chapters in this issue of Neuropsychopharmacology Reviews: The Next Generation of Progress reveal the impressive strides made recently toward understanding the basis of mental illness that could lead to new more powerful diagnostic and therapeutic modalities. The excitement surrounding these developments has been evident in

${ }^{*}$ Correspondence: Dr PS Wang, Division of Services and Intervention Research, National Institute of Mental Health, 6001 Executive Blvd., Room 7141, Rockville, MD 20852, USA, Tel: +1301443 6233,

E-mail: wangphi@mail.nih.gov

Received 9 April 2008; revised 25 August 2008; accepted 27 August 2008 communications by the Director of the National Institutes of Health (NIH), Dr Elias Zerhouni:

"National Institutes of Health researchers have also pioneered powerful new research tools such as highthroughput DNA sequencing, protein identification, expression arrays, and imaging technologies. These tools have greatly accelerated the research process, spurred progress, and spawned new hypotheses and discoveries in all areas of biomedical research. Perhaps nowhere else have the technological advances in imaging and genotyping elicited more excitement than in mental and behavioral health, for which NIH supported investigators have recently elucidated genes linked to schizophrenia, depression, bipolar disorder, and anxiety. In combination with functional brain imaging, researchers can now evaluate the brain circuitry involved in thinking, affective expression, and a broad range of behaviors" (Zerhouni, 2005).

However there continue to be challenges to achieving the promise and benefits of these innovations-namely, translating them into improved treatments and clinical outcomes for patients. In the remainder of this article, we describe how these challenges can be overcome by two types of translational research-from basic science into clinical developments and from clinical developments into practice. Promoting both translational research agendas has been an important guiding principle behind the research supported by several divisions within the National Institute of Mental 
Health (NIMH; Insel, 2006a). We then provide examples of translational research specifically in the area of schizophrenia and other psychotic disorders. In doing so, we pay tribute to the late Wayne Fenton, MD, the first Director of the Division of Adult Translational Research at NIMH, whose lifelong efforts and tragic death emphasize the urgent need for improved treatment of patients with these disorders (Insel, 2006b).

\section{DEFINING TRANSLATIONAL RESEARCH}

The Institute of Medicine's (IOM) Clinical Research Roundtable identified two major obstacles that impede efforts to apply rapidly science to better human health (Sung et al, 2003). The first of these 'translational blocks' occurs in the transfer of new understandings of disease mechanisms gained in the laboratory into the development of new methods for diagnosis, therapy, and prevention and their first testing in humans. The second of these translational blocks occurs in the translation of results from clinical studies into everyday clinical practice and health decisionmaking. To overcome these blocks, the IOM's Roundtable recommended that a variety of stakeholders take steps to support two types of translational research that have come to be referred to as 'T1' and 'T2' (Woolf, 2008). The goal of $\mathrm{T} 1$ research is to translate discoveries in the basic sciences into new diagnostic, secondary preventive, and primary preventive interventions; the goal of $\mathrm{T} 2$ research is to then take these clinical developments and ensure that they are delivered and received in actual practice.

\section{NEEDS FOR TRANSLATIONAL RESEARCH IN SCHIZOPHRENIA AND OTHER PSYCHOTIC DISORDERS}

The first antipsychotic medication, chlorpromazine, was synthesized in 1954 and launched the modern era of pharmacotherapy for psychotic disorders (Schatzberg and Nemeroff, 2006). Numerous 'first-generation' neuroleptic drugs that all blocked dopamine-2 receptors in the central nervous system were subsequently developed. A newer 'second-generation' of antipsychotic medications has been developed beginning with clozapine in the 1970s; these promised to improve upon the earlier conventional drugs, leading to them being called 'atypical' agents. Although most atypicals are indistinguishable except for their side-effect profiles, one agent, clozapine, has been shown to possess superior efficacy for refractory schizophrenia but also increase the risk for agranulocytosis (Kane et al, 1988).

\section{Needs for T1 Translational Research}

In spite of this half century of developments, many patients receiving antipsychotic medications fail to achieve either short-term recovery from psychotic episodes or long-term recovery of their functioning. Response during an acute drug trial is usually defined in terms of percentage reduction in a rating scale measure of positive or negative symptoms compared to baseline. These 'responders' to treatment may continue to exhibit clinically significant problems in one or more domains. Measures of remission and recovery are being incorporated into outcome assessment of treatments for major depression but have not been widely adopted as more stringent end points in clinical trials of schizophrenia (Honer et al, 2007). Functional impairment, which may persist despite a diminution in psychotic symptom, is not always taken into account when evaluating the benefit of the intervention.

Clearly there are great needs for $\mathrm{T} 1$ research uncovering new treatments for patients with schizophrenia and psychotic disorders and developing these treatments for clinical use (Fenton et al, 2003). One such need is for early identification of individuals at high risk, so that interventions can be tried earlier and at optimal developmental stages to avert subsequent psychopathology and disability. Another is uncovering new targets for intervention that go beyond just the traditional positive symptoms of psychotic disorders. Likewise, it is imperative to harness the promise of new therapeutic innovations - and even some existing ones that have not been exploited. Finally, successfully pursuing a T1 research agenda for schizophrenia and other psychotic disorders will necessarily involve new developments for testing interventions in early phase clinical trials, including progress in trial recruitment, methods for early signal detection, and addressing regulatory issues necessary for successful registration of treatments.

\section{Needs for T2 Translational Research}

T2 research is also urgently needed. In the absence of information on the effectiveness of treatments in real-world populations - especially compared to available alternatives-practice decisions are often made on the basis of efficacy and safety data that may not represent the outcomes achievable in typical practice. Earlier randomized controlled clinical trials suggested that atypical antipsychotics were less likely than conventional neuroleptics to cause extrapyramidal symptoms and were possibly more efficacious for negative symptoms (Leucht et al, 1999). On the basis of such data as well as promotion of atypicals as being safer and more tolerable, atypical use increased rapidly during the second half of the 1990s until it accounted for the majority of antipsychotic use (Wang et al, 2000), years before findings from comparative effectiveness trials became available (Lieberman et al, 2005). When even RCT data do not exist, practice decisions rely on anecdote or clinical judgment. For example, by the late 1990s more than one in six patients with schizophrenia spectrum disorders were being given standing regimens of multiple concurrent antipsychotics, despite the lack of data on the effectiveness or safety of this practice (Wang et al, 2000). Emerging evidence suggests the polypharmacy regimen of clozapine 
plus risperidone may not be superior to clozapine alone (Honer et al, 2006).

Such rapid adoption of new regimens before sufficient clinical effectiveness data are available has contributed to increasing health care expenditures, especially for public programs such as Medicare and Medicaid (Zerhouni, 2005). Expenditures on just atypicals account for nearly $30 \%$ of total drug costs in some Medicaid programs (Polinski et al, 2007). In the absence of clear data on the effectiveness and safety of antipsychotic regimens, programs are left uncertain if such expenditures are justified. An analysis of prior authorization policies used by Medicaid programs to control drug costs found no consistent relationship between a program's overall spending on atypicals and the application of these policies, suggesting there is not sufficient information on comparative effectiveness for programs to decide if atypical use should be encouraged or discouraged (Polinski et al, 2007). This study also found that after a 2005 FDA advisory warning of increased mortality among elderly patients with dementia taking atypicals, no state Medicaid program changed its prior authorization policy in response. This again suggests there may be insufficient data on the risks and benefits from regimens to inform policy makers' decisions (Polinski et al, 2007).

Finally, T2 research is urgently needed because, in spite of the large health care expenditures being made on antipsychotic medications, the vast majority of those suffering from schizophrenia and other psychotic disorders in the United States are inadequately treated and experience poor outcomes (Wang et al, 2002a). Likewise, international comparisons reveal that the United States lags behind many other developed nations in terms of the rate at which those with psychotic disorders are effectively, treated despite spending the greatest percentage of GDP on health care (Wang et al, 2007).

\section{Needs for Better Linkage and Coordination Between T1 and T2 Research Efforts}

Clearly, both T1 and T2 translational research are capable of and ultimately will be needed to achieve large gains in health outcomes at the population level (Woolf and Johnson, 2005). However, some investigators such as Woolf (2008) have astutely pointed out that although T1 and T2 share the name 'translational' research, they frequently involve distinct goals, research settings, study designs, and investigators; in fact, T1 and T2 research agendas may even seem at times to compete with one another for priority and resources. For these reasons, other investigators have elaborated on the traditional two-part model of translational research. One recent example proposed by Westfall et al (2007) employs a three-part schemata, with 'T1' consisting of case series as well as phase 1 and 2 clinical trials, 'T2' consisting of phase 3 and 4 clinical trials as well as observational and survey research, and ' $\mathrm{T} 3$ ' consisting of dissemination and implementation research. What such efforts to conceptualize translational research make clear is that there would be substantial benefits from better linkage and coordination between $\mathrm{T} 1$ and $\mathrm{T} 2$ research agendas, rather than consideration of them separately. For example the three-part model proposed by Westfall et al (2007) explicitly calls for more practice-based research and practice-based networks as forms of translational research to better bridge these current discontinuities. Although we will not adopt one of these more elaborate schemata of translational research in this article, the remainder of this article focuses not only on examples of $\mathrm{T} 1$ and $\mathrm{T} 2$ translational research in schizophrenia and other psychotic disorders, but also initiatives that can bridge the two.

\section{EXAMPLES OF TRANSLATIONAL RESEARCH IN SCHIZOPHRENIA AND OTHER PSYCHOTIC DISORDERS}

\section{Translating Discoveries from the Basic Sciences into New Interventions}

T1 translational researchers have made important discoveries recently into the potential mechanistic underpinnings of schizophrenia that hold great promise for the development of novel therapeutic agents, including those that can modify altered nicotinic acetylcholine (Freedman et al, 2008) $\gamma$-aminobutyric acid (Lewis et al, 1999), metabotropic glutamate (Moghaddam, 2004), and $\mathrm{N}$-methyl-D-aspartate receptor function (Krystal et al, 2003). Unfortunately, it is beyond the intended scope of this article to provide detailed or comprehensive coverage of these and other promising $\mathrm{T} 1$ innovations (eg novel psychosocial interventions). However the accompanying paper in this issue of Neuropsychopharmacology Reviews by Brady et al does expertly covers several watershed NIMH T1 initiatives that have been launched in schizophrenia and other psychotic disorders. These include the Measurement and Treatment Research to Improve Cognition in Schizophrenia program to develop measures of neurocognitive impairments for clinical trials of cognition-enhancing treatments; the related Cognitive Neuroscience Approaches to Treatment Development for Impaired Cognition in Schizophrenia initiative to develop, adapt, and implement measurement approaches from cognitive, social, and affective neuroscience for use in clinical trials; and the Treatment Units for Research on Neurocognition and Schizophrenia clinical research network to evaluate the safety, efficacy, pharmacokinetics, and pharmacodynamics of new cognition-enhancing agents. Readers interested in additional information on these and other examples of $\mathrm{T} 1$ research initiatives are referred to the accompanying article by Brady et al.

\section{The NAPLS Study to Identify Multiple High-Risk Targets for Earlier Preventive Interventions}

As mentioned above, capitalizing on the clinical innovations from $\mathrm{T} 1$ research will also require translational research that better links T1 and T2 scientific agendas. For example, such 
'intermediate' translational research could help ensure that new interventions are also optimally intensive, targeted, and cost-effective; ideally, such bridging translational research would take place before $\mathrm{T} 2$ research is conducted to turn innovations into everyday clinical practice and inform health decision-making. For disease processes that involve multiple determinants, designing optimally intensive interventions may require inclusion of a combination of active components. Toward such ends, the approach used in the recently completed North American Prodrome Longitudinal Study (NAPLS) to identify multiple high-risk targets for earlier preventive interventions is illustrative (Cannon et al, 2008). In NAPLS, the risk for conversion to psychosis was 35\% with a decelerating rate of transition during the 2.5-year follow-up period. Five features assessed at baseline contributed uniquely to the prediction of psychosis, including a genetic risk for schizophrenia with recent deterioration in functioning, higher levels of unusual thought content, higher levels of suspicion - $\theta$ paranoia, greater social impairment, and history of drug abuse. Prediction algorithms combining two or three of these variables resulted in dramatically increased predictive accuracy (ie $68-80 \%$ ) comparable to that in other areas of preventive medicine.

\section{The TEOSS Study of Antipsychotics in Early Onset Schizophrenia Spectrum Disorders}

Properly targeting and timing future interventions will also require additional programs of research to uncover opportune subgroups and developmental stages in which to apply interventions. The Treatment of Early-Onset Schizophrenia Spectrum Disorders (TEOSS) study is one NIMH-funded effort designed to shed new light on the efficacy, safety, and tolerability of intervening with one of two atypical antipsychotics (risperidone and olanzapine) vs a first-generation antipsychotic (molindone) in youth (8-19 years old) with schizophrenia spectrum disorders - an age strata for whom there is a dearth of comparative trials of antipsychotic agents (Frazier et al, 2007; McClellan et al, 2007). The TEOSS study also illustrated some of the challenges to conducting translational research with this population, including the need to overcome diagnostic/ assessment issues, safety concerns, and treatment adherence and retention problems. A planned interim analysis revealed significantly greater weight gain with olanzapine than with risperidone or molindone, and the Data and Safety Monitoring Board concluded that the inclusion of additional participants in the olanzapine arm would not provide sufficient additional information on efficacy to justify the potential risks, and randomization to olanzapine treatment was discontinued (McClellan et al, 2007). The results of the completed study $(N=116)$ are pending.

\section{The TEAM Study of Antipsychotics in Youth with Bipolar Disorder}

Antipsychotic agents are also increasingly used for other conditions in youth despite the paucity of data on their efficacy and safety for such purposes. To shed light on the safety, tolerability, and efficacy of antipsychotics in youth (6-15 years old) with bipolar disorder or symptoms of mania, the Treatment of Early Age Mania (TEAM) study will compare the atypical antipsychotic risperidone to lithium carbonate (an antimanic agent) or valproate (an antiepileptic). Likewise, antipsychotic medications are also increasingly being used to treat severe behavioral disturbances (eg aggression, tantrums, and self-injury) in individuals with developmental disorders. For this reason, the Research Units on Pediatric Psychopharmacology (RUPP) Autism Network evaluated the safety, tolerability, and efficacy of an 8-week trial of the atypical antipsychotic risperidone in 5- to 17-year-old children with autistic disorder $(N=101$; McDougle et al, 2000). Results revealed significant decreases in aggression, tantrums, and selfinjurious behavior, as well as improvements in stereotypic behavior and hyperactivity, which were maintained during the 4-month maintenance treatment (RUPP) Autism Network. Treatment with risperidone was associated with significant weight gain (average of $2.7 \pm 2.9 \mathrm{~kg}$ ), and weight gain was associated with mildly to moderately increased appetite. No children were withdrawn from the study due to weight gain. Still pending are results from an examination of associations between weight gain and common variants in several dopamine system genes.

\section{The Biomarkers Consortium and other Efforts to Personalize Interventions}

Developments in pharmacogenomics and other translational research to personalize treatments will also help target interventions to those most likely to respond and least likely to experience adverse effects. As covered in the accompanying article by Brady et al, the Biomarkers Consortium is a public-private biomedical research partnership to search for and validate new biomarkers to accelerate the competitive delivery of successful new technologies, medicines, and therapies for prevention, early detection, diagnosis, and treatment of disease (The Biomarkers Consortium, 2007). Part of this Biomarkers Consortium effort supported a whole-genome association study to identify biomarkers for treatment response in the $\mathrm{NIMH}$-supported large practical clinical trials. When such efforts yield promising pharmacogenomic and other biomarkers of response and side effects, deciding if such innovations are ready for full-scale efficacy testing can be facilitated by applying methods from the decision sciences. For example, a recent cost-effectiveness analysis was conducted by Perlis et al (2005) to evaluate a putative genetic test based upon six polymorphisms that predicted clozapine responsiveness in $77 \%$ of patients with schizophrenia. This analysis showed that clinically applying a genetic test with this predictive ability (and using clozapine as a first-line agent in those predicted to respond while reserving it for third-line use in those not predicted to respond) would cost $\$ 47705$ per quality-adjusted life-year 
(QALY) gained. These results are within the $\$ 50000$ per QALY benchmark typically used to determine whether health care interventions are worth investing in and suggest that if pharmacogenetic tests with comparable test parameters and costs were to become available, they would be worthy of testing in larger clinical trials.

\section{Turning Clinical Developments into Improved Practice and Informed Decision-Making}

Recent advances in study populations, databases, designs, and analytic methods have all expanded the armamentarium available to conduct T2 research. Practical clinical trials (March et al, 2005; Tunis et al, 2003) can be conducted to compare clinically relevant alternative regimens on a broad range of outcomes in typical patients. Establishing practicebased clinical trial networks can also greatly assist in recruiting adequate numbers of representative patients for practical clinical trials (Lieberman et al, 2005; Sachs et al, 2007; Trivedi et al, 2006). Other advances such as adaptive designs and cluster randomization (Glynn et al, 2007; Murphy et al, 2007) offer additional means for conducting future effectiveness trials. Because trials are not always feasible, affordable, or in some cases ethical, clinical epidemiologic and other clinical effectiveness research will also be needed. A variety of data from the general population and clinical samples could be used for observational studies of the effectiveness of treatments (Wang et al, 2000, 2005a; Wang and Walker, 2002b), although doing so will also require new analytic methods that offer enhanced control for confounding (Brookhart et al, 2007; Sturmer et al, 2007). Likewise, methodologic advances will make it increasingly possible to conduct quasi-experimental and simulation studies (Gold et al, 1996; Schneeweiss et al, 2001). Below, we describe examples of each of these to illustrate T2 research that may now be possible in schizophrenia and other psychotic disorders.

\section{The NIMH CATIE Trials}

The largely industry-sponsored efficacy trials of antipsychotics that have been available present an at times confusing picture of the relative benefits and risks of these agents (Heres et al, 2006). For this reason, NIMH supported the Clinical Antipsychotic Trial of Intervention Effectiveness (CATIE) trials. The CATIE schizophrenia study was designed to be an effectiveness rather than efficacy trial involving a large (1460) number of typical patients with chronic schizophrenia drawn from 57 diverse practice sites. In phase I, patients were randomized to one of four atypical agents (olanzapine, quetiapine, risperidone, and ziprasidone) or the conventional drug, perphenazine. On the primary outcome of all-cause discontinuation, $\frac{3}{4}$ of patients were unable to remain on their treatments due to inefficacy or intolerable side effects by 18 months (Lieberman et al, 2005). Olanzapine was the most effective but also associated with greater weight gain, decreases in insulin sensitivity, and dyslipidemia. The conventional antipsychotic, perphenazine, was comparable in efficacy to the remaining atypicals but associated with more discontinuation from extrapyramidal side effects. A subsequent cost-effectiveness analysis (Shorr et al, 1994) showed that treatment with perphenazine was associated with generally comparable effectiveness as the second-generation medications but 20 $30 \%$ lower health care costs.

Antipsychotics are also frequently prescribed to elderly patients with dementia to control behavioral and psychotic symptoms (Alexopoulos et al, 2004; Briesacher et al, 2005; Jeste et al, 2005; Kindermann et al, 2002; Shorr et al, 1994; Sink et al, 2005). To better understand the relative benefits and risks of such practices, an NIMH-supported comparative effectiveness trial of atypical antipsychotics in Alzheimer's dementia patients - the CATIE-AD trial-was conducted. A total of 421 outpatients from 42 practice sites were randomized to olanzapine, quetiapine, risperidone, or placebo and followed for up to 36 weeks. No differences were found between arms on the primary outcome of time to all-cause discontinuation. Olanzapine and risperidone appeared to possess superior efficacy than quetiapine or placebo, but these advantages were offset by more adverse effects (Schneider et al, 2006). A cost-effectiveness analysis of the CATIE-AD trial showed no differences in effectiveness between active treatments or placebo but significantly lower health care costs for placebo (Rosenheck et al, 2007).

\section{Clinical Epidemiologic Studies of Mortality from Antipsychotics in the Elderly}

The large number of typical patients drawn from diverse practice sites and observed over long follow-up periods also contributed to high costs in the CATIE trials, which were in excess of $\$ 50$ million. Although comparative effectiveness trials will continue to be essential for answering the many urgent public health questions regarding antipsychotic medications, alternative methods are also needed when conducting large practical clinical trials may be impossible due to their costs, the time required for completion, and other challenges. Clinical epidemiologic studies are one potential option when effectiveness trials are not possible, as illustrated by a recent study of the short-term mortality associated with conventional antipsychotic use by elderly patients. A 2005 FDA advisory warned of increased risks of short-term mortality associated with use of the atypicals aripiprazole, olanzapine, quetiapine, and risperidone compared to placebo in 17 RCTs among elderly dementia patients (US Food and Drug Administration, 2005). A significant increased risk of death for atypical antipsychotics $v s$ placebo was also found in a meta-analysis by Schneider et al (2005) of 15 short-term RCTs. 'Black box' warnings were added to the labels of all atypical antipsychotics describing these risks and advising that atypicals are not approved for behavioral symptoms from dementia. However, because of insufficient trial data on the mortality associated with conventional antipsychotic use in elderly 
dementia patients, the FDA did not include these agents in its advisory (Kuehn, 2005; US Food and Drug Administration, 2005). Although some investigators have suggested that conventional agents could in theory pose greater risks than atypicals in older populations, clinicians might have simply switched elderly patients back to these older agents in response to the FDA's warnings, particularly as their replacement by the newer drugs occurred relatively rapidly and recently (Chan et al, 1999; Dewa et al, 2002; Lawlor, 2004; Maixner et al, 1999; Strong, 2005; Tariot, 1999).

A clinical epidemiologic study based on data from the largest state pharmacy benefit program for the elderly found that those initiating conventional agents had a $37 \%$ greater dose-dependent risk of short-term mortality than those prescribed atypical antipsychotics (Wang et al, 2005b). These results persisted, both when alternative analytic methods were used to control for confounding (eg multivariate Cox models, propensity-score adjustments, and an instrumental variable analysis based on the prescribing physician's preference for conventional or atypical antipsychotics as the instrument (Brookhart et al, 2007) as well as in confirmatory analyses in other populations and databases (Schneeweiss et al, 2007). However, as unadjusted confounding cannot be completely excluded in clinical epidemiologic studies, the finding from a meta-analysis of RCTs that the conventional agent, haloperidol, increased short-term mortality $v s$ placebo by a relative risk numerically greater than that seen for atypical agents provides some further reassurance concerning the internal validity of these clinical epidemiologic findings (Schneider et al, 2005).

\section{Quasi-Experimental Studies of Limiting Psychotropic Prescription Benefits}

Quasi-experimental studies are another promising means for conducting T2 research when trials are not possible, particularly to inform the design of sound public policies. One illustrative example by Soumerai et al (1994) examined the impacts of a three-prescription-per-month cap on psychotropic drugs for Medicaid patients with schizophrenia. Interrupted time-series regression analyses were employed to examine changes in the rates of medication and other health care utilization - from a baseline 14 month period before the prescription cap's implementation, to the 11 months during its application, as well as to a 17 -month period after the cap was discontinued. A comparison cohort from a state with no restrictions on drug reimbursement during the study periods was also used to control for background temporal trends in the use of psychotropic medications and other forms of health care.

This study found that capping psychotropic prescription drug coverage was associated with not only significantly reduced antipsychotic medication consumption, but also a significant increase in the frequency of visits to community mental health centers as well as a sharp increase in the use of emergency mental health services and partial hospitalizations. Use of antipsychotic and other psychotropic medica- tions, as well as most mental health services, did generally return to their baseline levels after the psychotropic prescription cap policy was abandoned. However, an accompanying economic analysis indicated the increase in total mental health care costs per patient to Medicaid during the cap exceeded the savings in drug costs by a factor of 17 .

\section{Simulation Studies of the Cost-Effectiveness of Using Clozapine as a First-Line Antipsychotic}

Clearly clinical epidemiologic and quasi-experimental studies could provide useful means for conducting T2 research when comparative effectiveness trials are not possible. However, many questions concerning the effectiveness of interventions may not be answerable, even by clinical epidemiologic or quasi-experimental designs. This is especially true for hypothetical strategies or practices for which empirical data are absent. In such situations, simulation studies may be the only alternative. One such hypothetical regimen involves using the atypical clozapine as a first-line agent. When clozapine was introduced, it was restricted in two unique ways because of concerns that it can cause agranulocytosis: first, it could only be given to patients who failed at least two trials of other antipsychotics; and patients were required to have their WBC counts checked weekly before receiving each week's prescription. Such requirements have led to underutilization of clozapine even for patients with treatment-resistant schizophrenia (Conley and Buchanan, 1997).

However, additional evidence has emerged as these restrictions were imposed. A meta-analysis (Wahlbeck et al, 1999) and other RCT data (Lieberman et al, 2003) on treatment-sensitive as well as treatment-resistant patients have found that clozapine may be superior at improving psychotic episodes and preventing relapse. Meanwhile, the risks from agranulocytosis have been found to be substantially lower than originally feared (Honigfeld et al, 1998), leading to reductions in the requirements for WBC monitoring and costs associated with clozapine treatment. Clozapine has been shown to be relatively free of extrapyramidal side effects and may even have therapeutic effects on tardive dyskinesia (Lieberman et al, 1991), and suicidality (Meltzer et al, 2003; Meltzer and Fatemi, 1995; Meltzer and Okayli, 1995; Walker et al, 1997). Finally, generic forms of clozapine have further lowered its cost.

Whether these potentially greater benefits as well as lower risks and costs justify allowing clozapine to be used as a possible first-line agent in treatment-sensitive patients remains a question for which empirical data are lacking. For that reason, a simulation model was used to assess the effectiveness and costs of using clozapine as a potential first-line treatment $v s$ continuing to restrict it to third-line use (Wang et al, 2004). A Markov model based upon available RCT and epidemiologic data was employed to track the clinical and economic outcomes of hypothetical cohorts given one of these clozapine strategies. Results of this simulation showed that using clozapine as a first- $v s$ 
third-line agent would lead to modest gains in life expectancy as well as quality-adjusted life expectancy. The resulting cost-effectiveness ratio of using clozapine first $v s$ third was \$24 100 per QALY, again, well within benchmarks typically used to determine whether health care interventions are worth investing in. However, it should be kept in mind that such simulations studies may not capture all of the relevant outcomes that can be affected by treatments (eg the model did not account for the negative metabolic effects of clozapine) nor should simulation studies be considered a substitute for rigorously conducted clinical trials (Lieberman et al, 2003).

\section{FUTURE DIRECTIONS}

As this chapter illustrates, the future needs for T1 and T2 research in schizophrenia and other psychotic disorders are both broad and deep. The accompanying article by Brady et al provides excellent examples of the expanded T1 research that will be crucial to take advantage of discoveries from the basic neurosciences and translate them into more efficacious diagnostic, preventive, and therapeutic interventions. However, successfully turning such innovations from $\mathrm{T} 1$ research into widespread health gains will also require additional important steps, including translational research better linking $\mathrm{T} 1$ and $\mathrm{T} 2$ agendas as well as T2 research to turn clinical innovations into everyday clinical practice and health decision-making.

Better linkage of $\mathrm{T} 1$ and $\mathrm{T} 2$ research in schizophrenia and other psychotic disorders would benefit from enhanced communication and coordination between the scientific agendas and investigators in these often separate areas. For example designing interventions that can be widely implemented in practice will require that they are optimally intensive, targeted, and cost-effective. This in turn will depend upon future research in multiple areas. For disease processes that involve multiple determinants, designing successful interventions in the future may require inclusion of a combination of active components. Toward these ends, the NAPLS initiative's approach of identifying multiple high-risk targets for earlier preventive interventions is illustrative. Properly targeting and timing future interventions will also benefit from additional programs of research such as in the TEOSS initiative to uncover opportune subgroups and developmental stages in which to apply interventions. Likewise, better targeting of interventions to those most likely to respond or least likely to experience adverse effects would be greatly aided by new developments in pharmacogenomics and other research to personalize treatments, such the TEAM and RUPPS efforts on antipsychotic medication use in children. Deciding if such innovations are ready for full-scale efficacy testing can then be facilitated by applying methods from the decision sciences, as illustrated by an example of a cost-effectiveness analysis of a putative pharmacogenomic test for clozapine responsiveness.
When new more efficacious diagnostic, preventive, and therapeutic interventions are successfully developed and tested - and even when only moderately efficacious ones exist - future T2 research will be critical to ensure that interventions are used effectively in practice as well as to inform policy and purchasing decisions regarding their use. Future effectiveness trials will be critical to identify optimal treatment regimens that are effective, safe, and tailored to maximally benefit typical patients. Comparative effectiveness trials - which can shed light on the relative merits of available regimens for a variety of stakeholders - may be especially needed (Congressional Budget Office, December 2007). Once such optimal treatment regimens are identified, additional $\mathrm{T} 2$ research will be necessary to ensure that they are not just effective but also feasible to implement in realworld health care systems, cost-effective from the perspective of likely purchasers, and capable of being widely disseminated. Methodologic advances in the decision sciences as well as development of common metrics to compare the effectiveness of interventions across conditions will be necessary for a variety of stakeholders to make informed policy and purchasing decisions. The ongoing NIH Roadmap PROMIS initiative that will develop measures of functioning and other patient-reported health outcomes that can be applied across disease states is an excellent example (PROMIS).

In conclusion, all these forms of translational research will clearly be needed to ultimately improve the health outcomes experienced by extremely vulnerable populations with schizophrenia and other psychotic disorders. Advances in the armamentarium available to both conduct and coordinate such $\mathrm{T} 1$ and $\mathrm{T} 2$ research provide grounds for optimism that these needs can and will be met in the future.

\section{DISCLOSURE/CONFLICT OF INTEREST}

Dr Wagner reports holding stock in Johnson and Johnson. Otherwise, the authors declare that, except for income received from their primary employer, no financial support or compensation has been received from any individual or corporate entity over the past 3 years for research or professional service and there are no personal financial holdings that could be perceived as constituting a potential conflict of interest. The views and opinions expressed are those of the authors and should not be construed to represent the views of any sponsoring organization, agencies, or the US Government.

\section{REFERENCES}

Alexopoulos GS, Streim J, Carpenter D, Docherty JP (2004). Using antipsychotic agents in older patients. J Clin Psychiatry 65(Suppl 2): 5-99; discussion 100-102; quiz 103-104.

Briesacher BA, Limcangco MR, Simoni-Wastila L, Doshi JA, Levens SR, Shea DG et al (2005). The quality of antipsychotic drug prescribing in nursing homes. Arch Intern Med 165: 1280-1285.

Brookhart MA, Rassen JA, Wang PS, Dormuth C, Mogun H, Schneeweiss S (2007), Evaluating the validity of an instrumental variable study of neuroleptics: can 
between-physician differences in prescribing patterns be used to estimate treatment effects? Med Care 45(10 Suppl 2): S116-S122.

Cannon TD, Cadenhead K, Cornblatt B, Woods SW, Addington J, Walker E et al (2008). Prediction of psychosis in youth at high clinical risk: a multisite longitudinal study in North America. Arch Gen Psychiatry 65: 28-37.

Recent work that identifies several factors that could be potential targets for early intervention.

Chan YC, Pariser SF, Neufeld G (1999). Atypical antipsychotics in older adults. Pharmacotherapy 19: 811-822.

Congressional Budget Office (December 2007). Research on the comparative effectiveness of medical treatments: issues and options for an expanded federal role. The Congress of the United States. Publication No.2975. Washington, DC.

Conley RR, Buchanan RW (1997). Evaluation of treatment-resistant schizophrenia. Schizophr Bull 23: 663-674.

Dewa CS, Remington G, Herrmann N, Fearnley J, Goering P (2002). How much are atypical antipsychotic agents being used, and do they reach the populations who need them? A Canadian experience. Clin Ther 24: 1466-1476.

Fenton WS, Stover EL, Insel TR (2003). Breaking the log-jam in treatment development for cognition in schizophrenia: NIMH perspective. Psychopharmacology (Berl) 169: 365-366

Foundation for the National Institutes of Health. The Biomarkers Consortium. http:// www.biomarkersconsortium.org/. Accessed 11 September 2008.

Frazier JA, McClellan J, Findling RL, Vitiello B, Anderson R, Zablotsky B et al (2007). Treatment of Early-Onset Schizophrenia Spectrum Disorders (TEOSS): demographic and clinical characteristics. J Am Acad Child Adolesc Psychiatry 46: 979-988.

Freedman R, Olincy A, Buchanan RW, Harris JG, Gold JM, Johnson L et al (2008). Initial phase 2 trial of a nicotinic agonist in schizophrenia. Am J Psychiatry 165: 1040-1047.

Example of an early phase clinical trial that sheds light on a promising new therapeutic target in schizophrenia.

Glynn RJ, Brookhart MA, Stedman M, Avorn J, Solomon DH (2007). Design of cluster-randomized trials of quality improvement interventions aimed at medical care providers. Med Care 45(10 Suppl 2): S38-S43.

Gold MR, Siegel JE, Russell Lb, Weinstein MC (1996). Cost-Effectiveness in Health and Medicine. Oxford University Press: New York.

Heres S, Davis J, Maino K, Jetzinger E, Kissling W, Leucht S (2006). Why olanzapine beats risperidone, risperidone beats quetiapine, and quetiapine beats olanzapine: an exploratory analysis of head-to-head comparison studies of second-generation antipsychotics. Am J Psychiatry 163: 185-194.

Honer WG, Thornton AE, Chen EY, Chan RC, Wong JO, Bergmann A et al (2006). Clozapine alone versus clozapine and risperidone with refractory schizophrenia. N Engl J Med 354: 472-482.

One of the few sources of experimental data on the effectiveness of antipsychotic medication polypharmacy for schizophrenia.

Honer WG, Thornton AE, Sherwood M, MacEwan GW, Ehmann TS, Williams R et al (2007). Conceptual and methodological issues in the design of clinical trials of antipsychotics for the treatment of schizophrenia. CNS Drugs 21: 699-714.

Honigfeld G, Arellano F, Sethi J, Bianchini A, Schein J (1998). Reducing clozapinerelated morbidity and mortality: 5 years of experience with the Clozaril National Registry. J Clin Psychiatry 59(Suppl 3): 3-7.

Insel TR (2006a). Translational research in the decade of discovery. Horm Behav 50 : 504-505.

Insel TR (2006b). Tribute to Wayne Fenton, MD (1953-2006). Schizophr Res 88: $1-2$.

Jeste DV, Sable JA, Salzman C (2005). Treatment of late-life disordered behavior, agitation, and psychosis. In: Salzman C (ed). Clinical Geriatric Psychopharmacology, 4th edn. Lippincott, Williams \& Wilkins: Philadelphia. pp 129-195.

Kane J, Honigfeld G, Singer J, Meltzer H (1988). Clozapine for the treatmentresistant schizophrenic. A double-blind comparison with chlorpromazine. Arch Gen Psychiatry 45: 789-796.

Among the first and most important pieces of clinical evidence revealing the superiority of clozapine for refractory schizophrenia.

Kindermann SS, Dolder CR, Bailey A, Katz IR, Jeste DV (2002). Pharmacological treatment of psychosis and agitation in elderly patients with dementia: four decades of experience. Drugs Aging 19: 257-276.

Krystal JH, D'Souza DC, Mathalon D, Perry E, Belger A, Hoffman R (2003). NMDA receptor antagonist effects, cortical glutamatergic function, and schizophrenia: toward a paradigm shift in medication development. Psychopharmacology (Berl) 169: 215-233.

Kuehn BM (2005). FDA warns antipsychotic drugs may be risky for elderly. JAMA 293: 2462

Lawlor BA (2004). Behavioral and psychological symptoms in dementia: the role of atypical antipsychotics. J Clin Psychiatry 65(Suppl 11): 5-10.
Leucht S, Pitschel-Walz G, Abraham D, Kissling W (1999). Efficacy and extrapyramidal side-effects of the new antipsychotics olanzapine, quetiapine, risperidone, and sertindole compared to conventional antipsychotics and placebo. A meta-analysis of randomized controlled trials. Schizophr Res 35 51-68.

Lewis DA, Pierri JN, Volk DW, Melchitzky DS, Woo TU (1999). Altered GABA neurotransmission and prefrontal cortical dysfunction in schizophrenia. Biol Psychiatry 46: 616-626.

Lieberman JA, Phillips M, Gu H, Stroup S, Zhang P, Kong L et al (2003). Atypical and conventional antipsychotic drugs in treatment-naive first-episode schizophrenia: a 52-week randomized trial of clozapine $v s$ chlorpromazine. Neuropsychopharmacology 28: 995-1003.

Lieberman JA, Saltz BL, Johns CA, Pollack S, Borenstein M, Kane J (1991). The effects of clozapine on tardive dyskinesia. Br J Psychiatry 158: 503-510.

Lieberman JA, Stroup TS, McEvoy JP, Swartz MS, Rosenheck RA, Perkins DO et al (2005). Effectiveness of antipsychotic drugs in patients with chronic schizophrenia. N Engl J Med 353: 1209-1223.

A landmark large practical clinical trial that shed light on the comparative effectiveness of first and second generation antipsychotic medications.

Maixner SM, Mellow AM, Tandon R (1999). The efficacy, safety, and tolerability of antipsychotics in the elderly. J Clin Psychiatry 60(Suppl 8): 29-41.

March JS, Silva SG, Compton S, Shapiro M, Califf R, Krishnan R (2005). The case for practical clinical trials in psychiatry. Am J Psychiatry 162: 836-846.

McClellan J, Sikich L, Findling RL, Frazier JA, Vitiello B, Hlastala SA et al (2007). Treatment of early-onset schizophrenia spectrum disorders (TEOSS): rationale design, and methods. J Am Acad Child Adolesc Psychiatry 46: 969-978.

McDougle CJ, Scahill L, McCracken JT, Aman MG, Tierney E, Arnold LE et al (2000). Research Units on Pediatric Psychopharmacology (RUPP) Autism Network. Background and rationale for an initial controlled study of risperidone. Child Adolesc Psychiatr Clin N Am 9: 201-224.

Meltzer HY, Alphs L, Green Al, Altamura AC, Anand R, Bertoldi A et al (2003). Clozapine treatment for suicidality in schizophrenia: International Suicide Prevention Trial (InterSePT). Arch Gen Psychiatry 60: 82-91.

Meltzer HY, Fatemi H (1995). Suicide in schizophrenia: the effect of clozapine. Clin Neuropharmacol 18: S18-S24.

Meltzer HY, Okayli G (1995). Reduction of suicidality during clozapine treatment of neuroleptic-resistant schizophrenia: impact on risk-benefit assessment. Am J Psychiatry 152: 183-190.

Moghaddam B (2004). Targeting metabotropic glutamate receptors for treatment of the cognitive symptoms of schizophrenia. Psychopharmacology (Berl) 174 39-44.

Murphy SA, Oslin DW, Rush AJ, Zhu J (2007). Methodological challenges in constructing effective treatment sequences for chronic psychiatric disorders. Neuropsychopharmacology 32: 257-262.

Perlis RH, Ganz DA, Avorn J, Schneeweiss S, Glynn RJ, Smoller JW et al (2005). Pharmacogenetic testing in the clinical management of schizophrenia: a decision-analytic model. J Clin Psychopharmacol 25: 427-434.

Polinski JM, Wang PS, Fischer MA (2007). Medicaid's prior authorization program and access to atypical antipsychotic medications. Health Aff (Millwood) 26 750-760.

Rosenheck RA, Leslie DL, Sindelar JL, Miller EA, Tariot PN, Dagerman KS et al (2007). Cost-benefit analysis of second-generation antipsychotics and placebo in a randomized trial of the treatment of psychosis and aggression in Alzheimer disease. Arch Gen Psychiatry 64: 1259-1268.

PROMIS http://www.nihpromis.org/default.aspx. Accessed 18 March 2008.

Sachs GS, Nierenberg AA, Calabrese JR, Marangell LB, Wisniewski SR, Gyulai L et al (2007). Effectiveness of adjunctive antidepressant treatment for bipolar depression. N Engl J Med 356: 1711-1722.

Schatzberg A, Nemeroff C (2006). Essentials of Clinical Psychopharmacology, 2nd edn. American Psychiatric Publishing Inc. Washington, DC.

Schneeweiss S, Maclure M, Walker AM, Grootendorst P, Soumerai SB (2001). On the evaluation of drug benefits policy changes with longitudinal claims data: the policy maker's versus the clinician's perspective. Health Policy 55: 97-109.

Schneeweiss S, Setoguchi S, Brookhart A, Dormuth C, Wang PS (2007). Risk of death associated with the use of conventional versus atypical antipsychotic drugs among elderly patients. CMAJ 176: 627-632.

Schneider LS, Dagerman KS, Insel P (2005). Risk of death with atypical antipsychotic drug treatment for dementia: meta-analysis of randomized placebo-controlled trials. JAMA 294: 1934-1943.

An important meta-analysis that revealed the risk of mortality from atypical antipsychotic medication use in elderly patients with dementia.

Schneider LS, Tariot PN, Dagerman KS, Davis SM, Hsiao JK, Ismail MS et al (2006). Effectiveness of atypical antipsychotic drugs in patients with Alzheimer's disease. N Engl J Med 355: 1525-1538. 
Shorr RI, Fought RL, Ray WA (1994). Changes in antipsychotic drug use in nursing homes during implementation of the OBRA-87 regulations. JAMA 271: 358-362.

Sink KM, Holden KF, Yaffe K (2005). Pharmacological treatment of neuropsychiatric symptoms of dementia: a review of the evidence. JAMA 293 596-608.

Soumerai SB, McLaughlin TJ, Ross-Degnan D, Casteris CS, Bollini P (1994). Effects of a limit on Medicaid drug-reimbursement benefits on the use of psychotropic agents and acute mental health services by patients with schizophrenia. N Engl J Med 331: 650-655.

Strong C (2005). Antipsychotic use in elderly patients with dementia prompts new FDA warning. Neuropsychiatry Rev 6: 1-17.

Sturmer T, Glynn RJ, Rothman KJ, Avorn J, Schneeweiss S (2007). Adjustments for unmeasured confounders in pharmacoepidemiologic database studies using external information. Med Care 45(10 Suppl 2): S158-S165.

Sung NS, Crowley Jr WF, Genel M, Salber P, Sandy L, Sherwood LM et al (2003). Central challenges facing the national clinical research enterprise. JAMA 289 1278-1287.

Tariot PN (1999). The older patient: the ongoing challenge of efficacy and tolerability J Clin Psychiatry 60(Suppl 23): 29-33.

Trivedi MH, Fava M, Wisniewski SR, Thase ME, Quitkin F, Warden D et al (2006). Medication augmentation after the failure of SSRIs for depression. N Engl J Med 354: 1243-1252.

Tunis SR, Stryer DB, Clancy CM (2003). Practical clinical trials: increasing the value of clinical research for decision making in clinical and health policy. JAMA 290 $1624-1632$.

US Food and Drug Administration. FDA Public Health Advisory: Deaths with antipsychotics in elderly patients with behavioral disturbances. Available at: www.fda.gov/cder/drug/advisory/antipsychotics.htm. Accessed 15 April 2005.

Wahlbeck K, Cheine M, Essali A, Adams C (1999). Evidence of clozapine's effectiveness in schizophrenia: a systematic review and meta-analysis of randomized trials. Am J Psychiatry 156: 990-999.
Walker AM, Lanza LL, Arellano F, Rothman KJ (1997). Mortality in current and former users of clozapine. Epidemiology 8: 671-677.

Wang PS, Aguilar-Gaxiola S, Alonso J, Angermeyer MC, Borges G, Bromet EJ et al (2007). Use of mental health services for anxiety, mood, and substance disorders in 17 countries in the WHO world mental health surveys. Lancet 370: 841-850.

Wang PS, Demler O, Kessler RC (2002a). Adequacy of treatment for serious mental illness in the United States. Am J Public Health 92: 92-98.

Wang PS, Ganz DA, Benner JS, Glynn RJ, Avorn J (2004). Should clozapine continue to be restricted to third-line status for schizophrenia? A decisionanalytic model. J Ment Health Policy Econ 7: 77-85.

Wang PS, Lane M, Olfson M, Pincus HA, Wells KB, Kessler RC (2005a). Twelvemonth use of mental health services in the United States: results from the National Comorbidity Survey Replication. Arch Gen Psychiatry 62: 629-640.

Wang PS, Schneeweiss S, Avorn J, Fischer MA, Mogun H, Solomon DH et al (2005b). Risk of death in elderly users of conventional vs atypical antipsychotic medications. N Engl J Med 353: 2335-2341.

An example of promising data analysis methods that may be needed to address potential bias in observational studies.

Wang PS, Walker AJ (2002b). The pharmacoepidemiology of psychiatric medications. In: Tsuang MT, Tohen M (eds). Textbook in Psychiatric Epidemiology, 2nd edn. Wiley: New York. pp 181-194.

Wang PS, West JC, Tanielian T, Pincus HA (2000). Recent patterns and predictors of antipsychotic medication regimens used to treat schizophrenia and other psychotic disorders. Schizophr Bull 26: 451-457.

Westfall JM, Mold J, Fagnan L (2007). Practice-based research — 'Blue Highways' on the NIH roadmap. JAMA 297: 403-406.

Woolf SH (2008). The meaning of translational research and why it matters. JAMA 299: $211-213$.

Woolf SH, Johnson RE (2005). The break-even point: when medical advances are less important than improving the fidelity with which they are delivered. Ann Fam Med 3: 545-552.

Zerhouni EA (2005). US biomedical research: basic, translational, and clinica sciences. JAMA 294: 1352-1358. 